\title{
A literatura colombiana CONTEMPORÂNEA EM ANÁLISE
}

\author{
Dana Milena CHAVARRO* \\ Wellington PINHEIRO**
}

\begin{abstract}
RESUMO: A partir das múltiplas possibilidades de abordar a paisagem da escrita colombiana - que é reflexo de uma realidade marcada por conflitos territoriais, pela presença de atores armados e pela ausência de acesso aos bens jurídico-sociais neste artigo, nos interessa fazer uma reflexão que permita correlacionar elementos da literatura, da memória, do esquecimento e do trauma dessa realidade social a fim de potencializar uma reflexão autêntica da realidade colombiana. Neste contexto mobilizamos o romance El Olvido que Seremos (2006) de Hector Abad Faciolince. Para tanto, realizamos, em primeiro lugar, uma abordagem historiográfica do contexto social e político colombiano onde se desenvolve a obra. Dois: apresentamos algumas características da literatura contemporânea daquele país, especificamente, do autor. Finalmente, refletimos especificidades da literatura do testemunho encontrada na obra em análise.
\end{abstract}

PALAVRAS-CHAVES: Esquecimento. Testemunho. Literatura Colombiana.

\section{Introdução}

\begin{abstract}
Ya somos el olvido que seremos.
El polvo elemental que nos ignora

y que fue el rojo Adán y que es ahora todos los hombres y que no veremos.
\end{abstract}

\footnotetext{
UFPE - Universidade Federal de Pernambuco. Programa de Pós-Graduação em Sociologia. Recife PE - Brasil. 50670-901 - danachabe@yahoo.com.

* FACOL - Faculdade Escritor Osman Da Costa Lins. Vitória de Santo Antão - PE - Brasil. 55612-275 pinheiraosociais@yahoo.com.br.
} 
Ya somos en la tumba las dos fechas del principio y del término, la caja, la obscena corrupción y la mortaja, los ritos de la muerte y las endechas. No soy el insensato que se aferra al mágico sonido de su nombre; pienso con esperanza en aquel hombre que no sabrá que fui sobre la tierra. Bajo el indiferente azul del cielo esta meditación es un consuelo. (Epitáfio, Jorge Luís Borges)

A literatura pode ser compreendida como um fenômeno da práxis que mobiliza o ator social a ressignificar criticamente a realidade social. Em outras palavras, para De Marco (2004), a literatura pode ampliar vozes capazes de testemunhar desigualdades, injustiças sociais e ausências de bens sociais fundamentais à consagração dos direitos humanos como a democracia, por exemplo. Neste contexto emerge, nas últimas décadas do século XX, a literatura do testemunho como uma modalidade da memória social, uma forma de pensar radical que faz da escrita uma arte, uma maneira de ser-viverescrever que denuncia fatos sobre fenômenos sociais dramáticos que advêm de Auschwitz, o qual para Seligmann-Silva (2003) expressa um acontecimento sócio-histórico em que o real não se deixa reduzir a meros fatos banais do cotidiano.

É deste contexto crítico-sócio-literário de denunciar o que não fomos capazes de simbolizar em tempo sombrio que emerge este artigo ${ }^{1}$. Nossa proposta de investigação emerge demonstrando a necessidade de refletir a literatura colombiana a partir de questões do testemunho. Tendo em vista as múltiplas possibilidades de abordar a paisagem da escrita social, neste caso, a literatura de testemunho colombiana, nosso texto estrutura-se sobre o seguinte objetivo: correlacionar elementos que envolvem literatura, memória, esquecimento e trauma oriundos de denúncias literário-sociais a fim de refletir como essa literatura potencializa um olhar reflexivo sobre a cena da escrita ${ }^{2}$ colombiana. A partir desta proposta mobilizamos

\footnotetext{
1 Este artigo emergiu de nosso testemunho sobre os processos de mobilização em prol da paz, compreendida como um bem simbólico-moral de uma nação (MAUSS, 2008), que vem sendo construído na Colômbia nos últimos anos. O mesmo também faz parte do nosso trabalho de doutoramento no Brasil. 2 A partir de ARFUCH (2010) compreendemos a cena da escrita como o contexto político-social onde foi desenvolvido o artesanato de escritura da obra em análise.
} 
o romance El Olvido que Seremos (2006) ${ }^{3}$, de Hector Abad Faciolince, como nosso texto de interlocução literária.

Para tal empreendimento pretendemos. Um: fazer uma apresentação historiográfica do contexto social e político colombiano onde se desenvolve a obra. Dois: apresentar algumas características da literatura contemporânea colombiana, especialmente, Hector Abad Faciolince. Finalmente, refletir a partir desse livro questões específicas do trauma, da memória e do testemunho mobilizada pelo edifício teórico da literatura do testemunho.

\section{A "Guerra Suja" na Cena da Escrita Colombiana: os Personagens da Corrupção, do Narcotráfico e dos Atores Armados}

Com a intenção de contextualizar as condições político-sócio-culturais de ambientação da obra interlocutora faz-se necessário apresentar algumas especificidades do cenário colombiano. No âmbito da organização política observamos que o governo teve importância para o contexto de El Olvido que Seremos. Sobre isso destacamos a figura do ex-presidente Belisario Betancourt que concedeu anistia em 1982 para grupos armados, promovendo maior abertura política para quem deixasse o mundo das armas (TIRADO MEJIA, 1989). Depois de conseguir efetivar diálogos com grupos de interesses distintos parecia que sua proposta de pacificação seria possível, contudo, com a emergência do Movimento 19 de Abril (M-19) - grupo guerrilheiro oriundo dos anos 1970 - esse país vivenciou um espantoso momento de violência que culminou com a invasão ao Palácio da Justiça em 1985. Fato que poderia destituir aquele presidente que ao conhecer os rumores de sua iminente saída promoveu densa retaliação conhecida por política do pulso firme, ou seja, optou-se pela solução armada para tentar resolver conflitos sociais (LEAL BUITRAGO; ZAMOSC, 1990, p.76).

Em três de agosto de 1984 foi proposto um tratado de trégua entre o governo da Colômbia e o Grupo M-19. Porém, o encontro marcado teve que ser reagendado pois um dos anistiados, o médico Carlos Toledo Plata, foi assassinado alguns dias antes do referido acordo ser assinado. A consequência desse fato gerou maior instabilidade política naquele país, porque o que poderia ser considerado um momento de paz para a nação, na verdade, ficou registrado como a "data oficial do início da guerra suja na Colômbia" (SEMANA, 1987, n.p.).

\footnotetext{
3 El olvido que seremos vem se transformando numa obra clássica da literatura colombiana. Foi traduzido em várias línguas (inglês, italiano, português, alemão, francês e holandês). Ganhou o prêmio WOLA-Duke em direitos Humanos nos Estados Unidos em 2012.
} 
A repercussão daquele tratado, em princípio, ganhava apoio institucional, no entanto o governo do presidente Virgilio Barco teve problemas com o desfecho final do acordo, sobretudo, pela repercussão promovida pelo assassinato do líder Luis Carlos Galán ${ }^{4}$. Com isso criou-se uma conjuntura que culminou com a declaração oficial da guerra contra os carteis do narcotráfico.

Invocando as faculdades presidenciais extraordinárias da legislação por decreto que lhe conferiam as disposições do "Estado de Sitio" já estipuladas na Constituição Nacional, anunciou que o governo renovasse a extradição sumaria de narcotraficantes ao exterior (LEAL BUITRAGO; ZAMOSC, 1990, p. 446-7, tradução nossa).

Com efeito, a violência política na Colômbia nas últimas décadas do século XX é um exemplo dos meios utilizados pelos narcotraficantes (notadamente o cartel de Medellín) para responder às investidas do governo e sua política de implementar a ordem jurídico-social, o que inviabiliza os negócios ilícitos. Esta violência denegriu a história do país em inumeráveis casos de assassinatos, sequestros, torturas, atos de corrupção, dentre outras catástrofes sociais. Uma das mortes mais lamentáveis e conhecida foi o homicídio do candidato à presidência da república Luís Carlos Galán, defensor da extradição dos narcotraficantes.

Além dos narcotraficantes, das guerrilhas e da corrupção que estavam presentes no próprio governo, compreendemos que existia também outro ator do conflito que é impossível deixar de lado em uma alusão sobre a história contemporânea da violência Colombiana, a saber: o paramilitarismo 5 .

Estes grupos ilegais nomeados por Gustavo Duncan (2006) como os Senhores da guerra têm como caraterística essencial o fato de ser um exército regional que abre para os cartéis urbanos as rotas do narcotráfico, na medida em que exerce uma espécie de governo paralelo em micro sociedade (bairros, povoados, etc.) onde a segurança e os impostos são monopolizados por eles. A diferença com as guerrilhas reside no aspecto de que os primeiros não pretendem derrocar o governo estabelecido, pelo contrário, defendem a implementação de uma ideologia neoliberal promovida pelo confronto armado financiado pelo narcotráfico.

A partir de escritores como Faciolince, é possível compreender como o mundo submerso da violência e da fragmentação de valores morais, por exemplo, constituem, em parte, a construção social da realidade desta nação. Esse fenômeno da violência fica evidente na obra em análise:

4 BANCO DA REPUBLICA. Disponível em: <http://www.bbc.com/mundo/noticias/2014/08/140817_ colombia_galan_legado_25_aniversario_aw.> Acesso em: 05 out. 2017.

5 Para maior compreensão dos paramilitares ver DUNCAN (2006). 


\section{A literatura colombiana contemporânea em análise}

No ano da sua morte a guerra suja, a violência, os assassinatos seletivos, estavam sendo fincados de forma sistemática na universidade pública, pois alguns agentes do estado e seus cumplices do estado paralelo consideravam que ali estava a semente e a seiva da subversão. Nos meses anteriores do assassinato, somente na sua querida Universidade de Antioquia tinham sido assassinados sete estudantes e três professores (FACIOLINCE, 2006, p. 614, tradução nossa).

Contextualizando essa realidade observamos na fala de um paramilitar: "Esse filho da p... (sic) foi um dos primeiros que nós matamos em Medellín" (FACIOLINCE, 2006, p. 627). Os paramilitares assassinaram na rua Argentina em Medellín o Doutor Hector Abad Gómez, um médico colombiano pioneiro da medicina preventiva, professor universitário da Universidade da Antioquia, fundador da Faculdade Nacional de Saúde Pública e líder defensor dos direitos humanos. A sua bravura era de utilizar a palavra como a única arma que sabia manejar.

Hector Abad Faciolince, filho do doutor Hector Abad, relata como seu pai mobilizou o governo pela luta a favor dos direitos humanos na Colômbia. Para aquele professor universitário, a medicina também se apreende na rua, nos bairros onde as pessoas ficam doentes, segundo ele, só estando ali, naqueles lugares, é possível entender as causas e as consequências das doenças. Talvez, assim seja menos difícil entender porque aquele humanista da medicina defendia com obsessão o acesso universal à agua potável para população menos favorecida. Fato que foi abordado no romance do seu filho. Desta maneira, El Olvido que seremos abrange o espaço literário-discursivo em que confluem simultaneamente a sociedade colombiana, a vida do romancista, a sua questão existencial e o traumático assassinato do seu pai.

\section{A Literatura Colombiana Contemporânea: As Heranças do Realismo Mágico}

O romance El olvido que seremos é uma obra característica da literatura de testimonio latino-americana, ao mesmo tempo, nosso livro de interlocução também é um espaço biográfico do autor em questão, ou seja, falar de Hector Abad Faciolince é falar de uma nova geração de literatos colombianos ao lado de Laura Restrepo, William Ospina, Santiago Gamboa, Fernando Vallejo.

Segundo Mejia Rivera (1999), esta lista poderia ser ampliada por autores clássicos denominados de escritores mutantes, ou seja, tal lista poderia aumentar se acrescentássemos aos intelectuais supracitados um conjunto de acadêmicos que têm como característica essencial adotar a trajetória consagrada do Realismo Mágico ${ }^{6}$

6 O Realismo Mágico é um movimento literário, surgiu em meados do século XX, nele há uma preocupação estilística e interesse de mostrar o irreal como parte do cotidiano. Gabriel Garcia Marques, 
proposta por Gabriel Garcia Marques. Para o intento da nossa reflexão, é importante compreendermos que uma das grandes virtudes desta geração se consistiu no fato de que eles conseguiram se distanciar do arquétipo do realismo, construindo um estilo de escrita singular, como também tiveram êxito ao correlacionar suas narrativas com suas próprias lembranças e contextos existenciais da sua realidade social. Assim sendo, observamos a emergência de uma escrita autêntica, que descreve mundos materiais e invisíveis do cotidiano. Enfim, observamos o alvorecer de uma escrita original do mundo da vida de tais autores mutantes. Ao nosso ver, este é o caso de Hector Abad Faciolince.

$\mathrm{Na}$ sua narrativa é fundamental compreender as variantes de um giro autobiográfico vivenciado no contexto sócio-literario do conflito armado colombiano. Diferençar seu relato testemunhal das obras contemporâneas implica uma pesquisa editorial. Neste contexto algumas obras merecem destaque, a saber: Mi confesión (2005), de Maurício Arangurem Molina; El patrón: vida y muerte de Pablo Escolar (1995), de Luis Cañón; Mi hermano Pablo (2013), de Roberto Escobar; por fim, ainda ressaltamos o título Amando a Pablo, odiando a Escobar (2017), de Virginia Vallejo. São publicações que foram editadas durante a mesma época em que foi escrito e editado o romance de Facioline (2006). Todas essas obras possuem o caráter testemunhal ao qual fazemos referência. Sem dúvida, algo relevante estava acontecendo, estávamos passando por momento confessional, no qual, aparentemente, todos queriam falar em primeira pessoa. A literatura colombiana naquele momento estava saturada por aventuras de narcotraficantes, brigas de sicários $^{7}$, máfia política, malícia da milícia e toda a verborragia "paisa". Tudo isso levou a uma proliferação de autobiografias de ex-sequestrados - de jornalistas e até ex-presidentes. Sobre isso é revelador atentar para as palavras Loaiza Cano (2008):

Cada uma destas obras tem algo ou muito de mitomania ou da megalomania. Definitivamente, todas são uma fraude. E ao lado desta literatura como uma quadrilha, marcha uma serie de novelas em que os protagonistas e até os vencedores, como se ainda não fosse suficiente os triunfos cínicos na realidade são assassinos e criminosos. Enfim, existe uma saturação de relatos no que as vítimas e os derrotados são só um efeito de decoração. Não é só da literatura que fala de violência, mas também de uma literatura que com a sua pobreza de linguagem, com as suas reiterações e ligeirezas é ela mesma violência. (LOAIZA CANO, 2008, p. 94, tradução nossa).

Júlio Cortázar e Mario Vargas Llosa são alguns dos autores hispano-americanos mais representativos. 7 São indivíduos que assassinam pessoas por interesse financeiro, popularmente, chamado de matador de aluguel.

8 O termo se refere às pessoas que residem na cidade de Medellín, sobretudo, na região conhecida como El Viejo Caldas: Antioquia, Risaralda e Caldas. 
Desta maneira a autor deixa claro a diferença entre o tipo de biografias que foran reproduzidas neste momento e o tipo de literatura em que, aparentemente, todos tinham direito de falar a partir de sua idiossincrasia. Nos idos de 2006 é publicado El Olvido que Seremos em que, com uma voz infantil e suave o autor narra sua relação com seu pai, que foi assassinado numa rua da cidade de Medellín nos anos de 1980 nas mãos de um sicário. Neste romance de testemunho Hector Filho fala do Hector pai. É uma construção cheia de memória, permeada de lembranças, simbologias e esquecimentos. O relato dos derrotados é recuperado pelo Eu a partir de outra forma de narrar. Aqui, em nossa opinião, encontra-se a dimensão política mobilizada do romance.

Além disso, essa novela testemunhal revela a cena da escrita do seu país, nela é possível compreender as especificidades dos processos de socialização colombiana, mostrando fragilidades dos tecidos sociais dos cidadãos que sofrem uma espécie de anomia social, um processo de fragmentação na compreensão e internalização das regras sociais, como nos diria Durkheim (1999). Paralelamente, o escritor faz uso da mnemotécnica localizando espacialmente o leitor, nomeando lugares importantes e identificando fatos históricos pontuais. A morte do pai, a sua própria dor, a perda, são fatos que o irrompem violentamente. Com isso fica evidente que o romance reconstrói as singularidades históricas do filho fraco que se reproduz na juventude do autor em questão.

\section{Trauma, História e Literatura: Sobre os Elementos Literários de El Olvido que Seremos}

A partir de autores como Arfuche (2010), Bosi (1994), Seligmann-Silva (2003), observamos que a dimensão do trauma, da história e da literatura, por um lado, guarda uma espécie de sinergia de vidas grafadas no papel; por outro lado, esses elementos literários provocam um desaguar das tramas mais profundas do humano, articulam, provocam e fazem emergir roteiros de existências passadas que mobilizam, ou melhor, animam a atitude crítica da práxis, da ação literária que ganha vida com as memorias materializadas e energizadas na escrita testemunhal. Para concretizar isso recorremos às palavras de Faciolince (2006):

Escrevo isto para Inês, o sítio que deixou nosso pai, que lhe deixou o avô, que the deixou meu bisavô e que construiu meu trisavô tirando mato com as suas próprias mãos. Retiro isto de dentro, todos estes recortes retiro deles como se fossem um parto, como se tira um tumor. Eu não vejo a tela do computador, eu respiro fundo e o vejo lá fora... passaram-se quase vinte anos desde que o mataram e durante 
estes vinte anos, cada semana, eu sinto que tinha um dever iniludível, não falo de vingar sua morte, mas sim, pelo menos de contá-la (FACIOLINCE, 2006, p. 755-6, tradução nossa).

Assim sendo, nessa passagem observamos a emergência de uma narrativa que conta a experiência da perda do pai vinte anos depois da sua morte. E mais: salvar do esquecimento a memória do pai que era para ele um arquétipo de humanismo que morreu pela defensa dos seus próprios ideais pela justiça social. Mesmo assim, o autor reconhece como o fato da escrita na sua vida tem a ver com seu pai e a ligação seminal que eles tiveram:

Acho que o único motivo pelo qual tinha sido capaz de manter-me na escrita todos esses anos e de enviar meus escritos à imprensa é porque sei que meu pai gostaria mais que ninguém de ler todas estas páginas que não conseguiu ler. Que não poderá ler jamais. É um dos paradoxos mais tristes da minha vida: quase tudo o que foi escrito por mim foi escrito para alguém que não pode ler-me. Este livro não é outra coisa que a carta para uma sombra (FACIOLINCE, 2006, p. 42, tradução nossa).

A morte do pai é anunciada uma e outra vez durante todo o extenso do romance, no entanto, mesmo sabendo como ia finalizar a narração, o fato é iniludível, o relato mostra uma interseção da própria vida do autor com a ligação vital que o mesmo nutre com seu pai, mas além do relato da morte acreditamos que a intenção dele não era somente a narração mesma da morte, pelo contrário, Faciolince (2006) com sua maneira peculiar de escrita, com todas as especificidades de descrever vivamente suas memórias acaba, com intensidade, exaltando as especificidades, as virtudes da própria vida.

O livro seria um exemplo no qual se articulam a necessidade de narrar a experiência vivida e a percepção da insuficiência da linguagem diante dos fatos (inenarráveis) e o caráter inimaginável (inverosimilhança) que é o que descreve o espaço de tensões sobre o qual a literatura de testemunho se pronuncia (SELLIGMANN-SILVA, 2003). As tristes palavras do filho, não são outra coisa que a mostra contundente da autobiografia na literatura colombiana, e mais ainda, de uma elaboração de trauma.

Assim, por um lado, o texto relata a vida de um menino de classe média que tinha todas as necessidades supridas, ou melhor, gozava de certo privilégio e conforto se comparado à média da sua sociedade tradicional. Por outro lado, a obra ressalta a presença marcante do catolicismo. Embora a história familiar se desenvolva de forma ficcional na primeira parte, observamos a representação micro da realidade histórica da Colômbia. 
Na casa viviam dez mulheres, um menino e um senhor. As mulheres eram a babá, que tinha cuidado da minha avó, tinha quase cem anos e estava meio surda e meia cega; duas moças do serviço doméstico - Emma e Teresa; minhas cinco irmãs - Maryluz, Clara, Eva, Marta e Sol - minha mãe e uma freira. O menino, eu, amava ao senhor, seu pai, sobre todas as coisas. $\mathrm{O}$ amava mais que a Deus (FACIOLINCE, 2006, p. 42, tradução nossa).

Por tudo isso somos convencidos a compreender a literatura de testemunho como uma relação entre a literatura e a sociedade. Com efeito, o relato no romance é posto a partir da singularidade do real que, em nossa percepção, tem dois elementos essenciais para serem destacados: Um: $O$ fato de ser uma narrativa que inicia a ação do romance com a escritura da infância do protagonista. Dois: A escrita singular é materializada por um exercício autobiográfico que produz memória no próprio texto do narrador e que se ocupa, ele mesmo, em um profundo exercício hermenêutico de configurar-se em protagonista do romance.

Sobre a escrita da infância compreendemos que ela configura o espaço pessoal mais distante do que narra o autor e, talvez seja essa a causa pela qual ele se permite iniciar assim a sua narrativa, mas isso também ativa a memória do homem adulto. No percurso da história a partir da escrita da infância, abre-se um espaço que dá um certo domínio ao narrador, pois ele é a voz de um menino que fala e que se percebe menino antes que o adulto que o habita volte à tona. Segundo Arfuch (2010), esse exercício de escrita profunda configura-se na escrita da práxis. Desta maneira produz-se efeito de verossimilhança na sua narrativa. Emerge um narrador em primeira pessoa por onde filtram-se todos os acontecimentos e é a partir desse olhar subjetivo da criança que se reflete em maior ou menor proporção a história nacional, ou melhor, surge uma maneira particular de narrar a história da Colômbia.

Isso nos leva a refletir também o fato autobiográfico. Leonor Arfuch (2010) afirma que no espaço biográfico contemporâneo e na autobiografia canônica há uma coincidência empírica entre narrador e autor, o que no caso em análise é evidente. $\mathrm{O}$ exercício com a cena própria da escrita também promove uma busca permanente de sentido da própria vida. Porque:

Seus assassinos continuam livres dia-a-dia, mais e mais poderosos e as minhas mãos não podem lhes combater. Somente meus dedos fincados numa tecla depois da outra podem dizer a verdade e declarar a injustiça. Uso a mesma arma: as palavras. Para quê? Para nada; ou para o mais essencial e simples: para que se conheça. Para alongar a sua recordação antes que chegue o esquecimento definitivo em mim (FACIOLINCE, 2006, p. 760, tradução nossa). 
Hector Abad Faciolince (2006) parece querer recuperar o seu Eu e o discurso daqueles que são assassinados a começar pela morte do pai que como muitos outros, nesse momento da história nacional, são mortos nas mãos dos paramilitares e estão condenados ao esquecimento.

Outro elemento que é interessante denotar dentro do espaço biográfico contemporâneo é a intertextualidade de que nos fala Arfuch, (2010). Como exemplo observamos a referência intertextual, a partir das narrativas da obra que tem nas palavras um elemento autobiográfico, a qual se contrapõe às diferentes formas de materialização da violência expressas no romance. Tal estrutura textual foi demostrada na passagem anterior. A mesma ótica de intertextualidade, talvez de forma menos direta, pode ser encontrada na primeira parte do romance, especificamente, numa secção bastante peculiar quando trata de uma anedota pessoal que o protagonista fez quando tinha por volta dos dez anos contra a família dos Manevich - uma família judia que vivia na mesma rua onde morava o autor em discussão.

Em certa parte do romance Faciolince (2006), novamente, faz alusão ao fenômeno de desumanização sofrido pelos judeus. Ele lembra das tramas infantis, principalmente, do fato de participar do que denominou de "noite dos cristais" para com os Manevich. Durante estas recordações o autor lembra com veemência a atitude do pai ao lhe contar todo o processo de insensatez vivenciado pelos judeus em diversos locais da Alemanha durante a Segunda Guerra Mundial. Essa ambientação do conflito permitiu-lhe fazer alusão aos discursos políticos contemporâneos a partir da memória narrada da sua infância. Neste último exemplo de intertextualidade, abre-se caminho também para pensarmos na menção feita no romance ao fato histórico de Shoah, em que recupera elementos chocantes daquela época. A menção desse ácido momento vivenciado pelos judeus tem a ver com a literatura do testemunho e com a noção de trauma que é parte de nosso interesse.

A escrita para-textual da infância também aparece, principalmente, pela figura material da fotografia da sua irmã estampada na capa do livro. O uso do recurso fotográfico proposto pelo autor apresenta de maneira análoga e enfática a experiência do Shoah e, principalmente, a sua vivência da violência na Colômbia. Quando o pai repreendeu aquela criança ele, dentre outras coisas, demonstrou como aquele comportamento era descabido e injustificado para com a família Manevich. Adentrando na obra percebemos isso da seguinte maneira:

\footnotetext{
9 A noite dos cristais representa um fato histórico de desumanização dos Judeus durante a Segunda Guerra Mundial. A noite vivenciada pelo autor consistiu numa espécie de brincadeira onde várias crianças praticavam atos discriminatórios para com os membros da família Manevich.
} 


\section{A literatura colombiana contemporânea em análise}

Observando aos meus olhos falou-me que o mundo ainda estava cheio de uma peste que se chamava antissemitismo. Contou-me o que os nazis haviam feito vinte cinco anos antes com os judeus e que tudo havia iniciado ao se jogar pedras nas vitrines durante a terrível Kristallnacht ou noite dos cristais. Depois mostroume umas imagens horríveis dos campos de concentração. (FACIOLINCE, 2006, p. 58, tradução nossa).

Seligmann-Silva (2003, p. 49) afirma que "Ao pensarmos Auschwitz, fica claro que mais do que nunca a questão não está na existência ou não da 'realidade', mas na nossa capacidade de percebê-la e de simbolizá-la”. É interessante e muito revelador que as páginas deste romance, na segunda parte, quando o narrador fala na voz do adulto, no mesmo parágrafo, alude às fotografias de sequestrados e torturados colombianos. A relação dos dois eventos de violência é direta. Faciolince (2006, p. 610) grafa esta relação de desumanização com um termo bastante curioso, "a nova peste". Uma ideia herdada do seu pai e que podemos compreender neste fragmento:

A sua noção da violência como uma nova tipologia da peste vinha de muito antes. Já no primeiro Congresso Colombiano de Saúde Pública, organizado por ele no ano de 1962 tinha lido um artigo que seria histórico na medicina social do país: sua palestra tinha por título "Epidemiologia da Violência" (FACIOLINCE, 2006, p.601, tradução nossa).

Com isso acreditamos que os comentários de Abad Faciolince e as ideias do pai, nos permite estabelecer uma conexão entre Shoah e a Guerra Suja no contexto colombiano. É relacionando estas duas mostras de desumanização e de antihumanismo que o autor encontra apoio político na sua empreitada por justiça social.

A menção aos desaparecidos na narrativa de Faciolince (2006, p. 524), é uma forma de denuncia das atrocidades e brutalidades cometidas contra uma grande parte da população colombiana: "A desaparição de alguém é um crime tão grave quanto o sequestro ou o assassinato e talvez, é mais terrível, pois a desaparição é incerteza, medo e esperança banal". Dessa forma, ao se relacionar alusivamente as passagens do livro com realidade análogas (semelhantes em maior ou menor grau) da sociedade, constrói-se uma maneira de reclamar por justiça.

Mesmo que a alusão aos desaparecidos seja textualmente explícita na parte da narrativa que corresponde ao narrador adulto, a menção aparece implícita desde o início do romance quando na escrita da infância o autor reflete acerca das possibilidades de que seu pai possa desaparecer em algum momento da vida. A sensação de medo e incerteza é conjecturada na criança que habita sua memória. Assim, as duas partes da narrativa, tanto a primeira sendo narrada pela criança 
como a segunda parte do adulto que inicia com o capítulo versando sobre a perda da sua irmã e, também no capítulo seguinte no qual narra a morte do pai, é possível encontrar um movimento argumentativo, um constante vaivém, um ir e voltar. Em outras palavras, observamos a construção potente de uma dialética permanente, na intenção escrita de Faciolince (2006), pelo direito à memória.

Na narrativa infantil a fala do pai, - que não gostava das armas e nunca quis pegá-las em vida -,nos permite compreender como o autor usava as palavras como arma, ou seja, ele materializava a herança de escrita do pai. Sobre a existência dessa herança em sua escrita de testemunho, observamos o fato dele incorporar os escritos do pai, de forma explicita denuncia a ineptidão e injustiça do governo, o que nos permite exemplificar como a memória, a crítica e a violência da sua nação estão presentes na cena da sua escrita.

Outro exemplo é que Faciolince (2006) reproduz em seu livro um artigo que foi publicado por seu pai em um jornal de abrangência nacional, pouco tempo depois que um amigo (do pai) foi encarcerado e torturado pelo exército de Medellín:

Eu acuso os interrogadores do Batalhão Bomboná de Medellín, de serem impiedosos torturadores sem alma e sem compaixão pelo ser humano, de serem psicopatas, de serem criminosos pagos, subsidiados pelos colombianos para reduzir os prisioneiros políticos, sindicais e sindicalistas às condições incompatíveis da dignidade humana, causadores de toda sorte de atrocidades, muitas vezes irredutíveis e irremediáveis [...] eu denuncio formal e publicamente estes procedimentos dos chamados mandos médios, de violentar sistematicamente os direitos de centenas de compatriotas nossos. (FACIOLINCE, 2006, p. 639, tradução nossa).

O autor também se vale de muitas referências intertextuais contextualizando a realidade alemã, latino-americana e espanhola, esta última, tem a ver com as recordações paternais de leituras compartilhadas. Seu pai tinha o hábito de leitura de cabeceira principalmente quando lia para ele "poemas de Machado, de Vallejo e de Neruda sobre a guerra civil espanhola" (FACIOLINCE, 2006, p.217). A menção de tais poetas além do denominador comum de contemplação literária colocava aquele garotinho a par da conjuntura política do fascismo espanhol.

A leitura desses poetas não fica só no fato político-histórico que parece ser outra constante dentro do romance. "Para a testemunha de um evento-limite, como o assassinato em massa perpetrado pelos nazistas, coloca-se - ou melhor, impõe-se uma questão incontornável: a 'opção' entre a 'literalidade' e a 'ficção' da narrativa” (SELIGMANN-SILVA, 2003, p. 47). Nesse sentido outros elementos chamam a atenção do romance. Dentre tantos, destacamos o fato existir a relação com a poética borgiana: O poema El olvido que seremos que segundo conta Faciolince (2006) 
tornou-se uma árdua pesquisa pelo fato de querer esclarecer a autoria do poema. Após um longo tempo de investigação ficou ratificado que o mesmo pertencia a Jorge Luís Borges. O soneto borgiano foi encontrado no bolso da jaqueta do pai no momento do seu assassinato nas mãos de paramilitares. Sendo esta, a poesia que movimenta, articula e dá o título ao romance. Ela faz parte do poema Epitáfio e aparece em citação direta na obra em análise ${ }^{10}$.

Com essa poesia, Faciolince (2006) alude à transitoriedade da existência humana e à fragilidade da memória. No entanto, entre a literalidade e a ficção, a cópia do seu romance encontra-se acompanhada por outro papel no qual estavam escritos os nomes das pessoas que foram ameaçadas pelos paramilitares como o próprio Abad Gómez. Esta coincidência no testemunho de um evento-limite entre a realidade e a ficção deixa marcada também uma espécie de denúncia contra a impunidade que ampara os senhores da guerra, naquele caso, os paramilitares. Em uma sociedade socializada com o fenômeno da violência observamos que esse testemunho constitui uma realidade dada, um desfecho sem espanto, na medida em que as pessoas já esperam pelo desfecho de fatos nos quais dores e ausências fazem parte da cena da escrita. Neste contexto, longe da justiça, espera-se o esquecimento (el olvido) dos fatos? Ou seja, o esquecimento dos fatos será suavizado com o passar (infinitamente) do tempo? El olvido que seremos emerge como um enérgico não da literatura de testemunho que se volta para denunciar fatos de desumanizam nossa maneira de constituir sentido no mundo.

\section{Conclusões}

A escrita deste romance em que o autor se impõe de alguma maneira vinte anos depois da morte do pai é um imperativo que vai mais além do testemunho da dor. É uma clara afirmação de testemunhar que existe necessidade de justiça através da narrativa. "O testemunho coloca-se desde o início sob o signo da sua simultânea necessidade e impossibilidade" (SELIGMANN-SILVA, 2003, p. 46).

O imperativo de Hector Abad Faciolince (2006) por contar a sua verdade pode ser interpretado como o desejo de fazer justiça com as suas próprias mãos, neste caso, através da escrita. Há também o fato da denuncia ser um contraponto à incapacidade do Estado de proteger os seus cidadãos. O ethos do texto emerge da memória do pai ausente, da memória de um sujeito social vítima de fatos que transcenderam suas próprias forças. Só o filho, testemunho dos fatos recorre à palavra sua arma/ferramenta para estabelecer, pelo menos temporalmente, a relação entre memória e justiça.

${ }_{10}$ Para efeito de gancho narrativo optamos por começar nosso artigo com o referido poema. 
Assim, trazemos para a reflexão a metáfora do cubo caracterizada por Hector Abad Faciolince (2006, p. 671) como uma "face oculta para todo o mundo, aos outros e a nós mesmos". Isso, ao nosso compreender, é uma representação simbólica de uma narrativa histórica inacessível, permeada por injustiças e rejeitada pelo Estado que não deu maiores esclarecimentos sobre este fato oculto da realidade político-social da Colômbia. Por isso, o desejo de reconhecer publicamente a face oculta e silenciada dos acontecimentos emerge no romance a necessidade que o protagonista sente de relacionar sua narrativa com a experiência traumática que durante vinte anos permaneceu latente na sua escrita-vida.

Com isso, observamos como El olvido que Seremos contribui significativamente para o campo da relação sociedade-literatura, na medida em que nos permite problematizar a impunidade e o esquecimento como elementos a serem questionados na realidade e na história colombiana e, de certo modo, latino-americana, pois, ainda lutam pela conquista da paz como um bem de justiça social. A importância dessa obra expressa por Holly Ackerman ${ }^{11}$ (jurada do prêmio WOLA, 2012, n.p.) tem a ver com o fato do romance poder potencializar nossa humanização, pois: "o livro renovou minha convicção de que a liberdade, a justiça e a paz no mundo têm por base o reconhecimento da dignidade intrínseca e dos direitos iguais e inalienáveis de todos os membros da família humana".

\section{An analysis of CONTEMPORARY Colombian literature}

ABSTRACT: Through the many possibilities available to understanding current Colombian literature - which is an echo of a reality marked by territorial disputes, by the presence of warlords and by the absence of judicial access - this article attempts to make a correlation between elements of literature, memory, loss of memory, and the trauma of this social reality, so as to allow a better understanding of Colombian reality. Through this frame of reference we analyze the novel El Olvido que Seremos (2005) by Hector Abad Faciolince. We start with a historical analysis of Colombia's social and political context. Next we present some of the important features of Colombian literature and, more precisely, of the author of the book. Finaly, we consider the specificities of testimonial literature that are present in the work in question.

KEYWORDS: Disremembering. Testimony. Colombian Literature.

\footnotetext{
11 Washington Office on Latin America - WOLA. Disponível em: <https://www.wola.org/2012/10/obliviona-memoir-by-hector-abad-wins-wola-duke-human-rights-book-award/>. Acesso em: 28 nov. 2017. 


\section{AGRADECIMENTO}

A construção deste texto tem como um dos pilares o incentivo mobilizado por nossa amiga Eliane. Dessa forma, tecemos um sincero agradecimento a esta amiga que de forma atenciosa e comprometida promoveu um tipo de formação que potencializou a compreensão epistemológica que temos da realidade social, como também ampliou o desejo de conhecimento sociológico para que possamos nos tornar um ser humano melhor.

\section{REFERÊNCIAS}

ARFUCH, Leonor. O espaço biográfico. Dilemas da subjetividade contemporânea. Rio de Janeiro: Eduerj, 2010.

BOSI, Ecléa. Memória e Sociedade: lembranças de velhos. São Paulo: Companhia das Letras, 1994.

DE MARCO, Valeria. A literatura de testemunho e a violência de Estado. Lua nova, n. 62, p. 45-68, 2004.

CAÑÓN, Luis. El Patron: vida y muerte de Pablo Escobar. Bogotá: Editorial Booket, 1995.

ESCOBAR, Roberto. Mi Hermano, El Patrón Escobar. Bogotá: Quintero Editores, 2013.

DUNCAN, Gustavo. Los Señores de la Guerra. Planeta: Bogotá: Planeta, 2006.

DURKHEIM, Emile. As regras do método sociológico. Tradução: Paulo Neves. São Paulo: Martins Fontes, 2007.

FACIOLINCE, Héctor Abad. EI olvido que seremos. Socrates (v1.0) ePub base v2.1, 2006.

LEAL BUITRAGO Francisco; ZAMOSC León. (1990) (edits.). Al filo del caos: crisis política en la Colombia de los años 80: memorias. Bogotá: Tercer Mundo, 1990.

LOAIZA CANO, Gilberto. La dignidad de la frágil palabra. Número, v. 56, p. 93, 2008.

MAUSS, Marcel. Ensaio Sobre a Dádiva. Tradução: Antônio Felipe Marques. Lisboa: Edições 70, 2008.

MEJIA RIVERA, Orlando. La generación mutante. Estudios de Literatura Colombiana, n. 4, p. 99-106, 1999.

MOLINA, Maurício Arangurem. Mi Confesión. Autobiografia de Carlos Castaño. Bogotá: Editorial: JVK Y CIA, 2005. 
SELIGMANN-SILVA, Márcio. (Org.). História, Memória, Literatura: O Testemunho na Era das Catástrofes. Campinas: UNICAMP, 2003.

SEMANA. La guerra sucia. Semana, Bogotá, 28 de sept. 1987. Disponivel em: $<$ http://www. semana.com/nacion/articulo/la-guerra-sucia/9387-3>. Acceso em: 19 ago. 2017.

TIRADO MEJÍA, Álvaro. (Dir.), Nueva historia de Colombia, Bogotá: Planeta, 1989.

VALLEJO, Virginia. Amando Pablo odiando Escobar. Bogotá: Giunti, 2017.

WOLA - Washington Office on Latin America. Oblivion: A Memoir by Hector Abad Wins WOLA-Duke Human Rights Book Award. WOLA, 12 de out. 2012. Disponível em: <https:// www.wola.org/2012/10/oblivion-a-memoir-by-hector-abad-wins-wola-duke-human-rightsbook-award/>. Acesso em: 28 nov. 2017.

Recebido em 11/02/2018.

Aprovado em 22/04/2018. 